\title{
Genetic Method for Labeling Electrically Coupled Cells: Application to Retina
}

\author{
Mu Qiao and Joshua R. Sanes* \\ Center for Brain Science and Department of Molecular and Cellular Biology, Harvard University, Cambridge, MA, USA
}

Understanding how the nervous system functions requires mapping synaptic connections between neurons. Several methods are available for imaging neurons connected by chemical synapses, but few enable marking neurons connected by electrical synapses. Here, we demonstrate that a peptide transporter, Pept2, can be used for this purpose. Pept2 transports a gap junction-permeable fluorophorecoupled dipeptide, beta-alanine-lysine- $N$-7-amino-4-methyl coumarin-3-acid (BALA). Cre-dependent expression of pept2 in specific neurons followed by incubation in $\beta A L A$ labeled electrically coupled synaptic partners. Using this method, we analyze light-dependent modulation of electrical connectivity among retinal horizontal cells.

Keywords: electrical synapse, gap junction, retina, horizontal cells, peptide transporter, PEPT2

\section{OPEN ACCESS}

Edited by:

Robert W. Burgess,

The Jackson Laboratory, USA

Reviewed by:

Marla B. Feller,

University of California, Berkeley, USA

Daniel Kerschensteiner,

Washington University in St. Louis,

USA

Franklin Caval-Holme contributed to the review of Marla B. Feller

*Correspondence: Joshua R. Sanes sanesj@mcb.harvard.edu

Received: 03 November 2015 Accepted: 11 December 2015 Published: 07 January 2016

Citation: Qiao M and Sanes JR (2016) Genetic Method for Labeling Electrically Coupled Cells: Application to Retina.

Front. Mol. Neurosci. 8:81. doi: 10.3389/fnmol.2015.00081

\section{INTRODUCTION}

Because neurons communicate with each other primarily through synapses, mapping patterns of synaptic connectivity is an essential step in understanding how neural circuits function. Synapses are of two types: chemical, in which neurotransmitter released by the presynaptic cell signals to its postsynaptic partner, and electrical, in which currents pass directly from cell to cell through gap junctions (Siegelbaum and Kandel, 2013). To date, chemical synapses have received the vast majority of attention (Sanes and Yamagata, 2009; Yogev and Shen, 2014). In contrast, patterns of electrical connectivity have been studied in relatively few cases (White et al., 1986; Volgyi et al., 2009; Varshney et al., 2011). In part, this inattention stemmed from the belief that electrical synapses were relatively rare in vertebrates. Over the past decade, however, it has become apparent that they are in fact numerous and play diverse roles in developing and adult animals (Connors and Long, 2004; Hormuzdi et al., 2004; Bloomfield and Volgyi, 2009; Cook and Becker, 2009; Li et al., 2012; Yu et al., 2012; Apostolides and Trussell, 2013; Zhu et al., 2013). It is therefore essential to redress the balance.

One obstacle to the study of electrical synaptic connections -perhaps both a cause and an effect of the scant attention they have been paid- is that few methods are available for mapping them in the intact nervous system. Electrical connectivity is most often assessed by impaling a neuron with a microelectrode for injection of a dye that diffuses through gap junctions (Vaney, 1991; Mills and Massey, 1994; Hoshi et al., 2006). This approach is laborious, and difficult to apply to cells that are small, fragile, or deeply buried in tissue. An alternative, intracellular recording of potentials evoked by stimulating a neighboring cell is even more difficult, because it faces the added obstacle of requiring paired recordings. Light microscopic immunohistochemical localization of individual electrical synapses is infeasible, both because gap junctions are often near the limit of optical resolution and because no single component is known that marks all and only electrical 
synapses. Electron microscopy provides sufficient resolution, but is hampered by the need to connect synapses to cells of origin through reconstruction from serial sections, which is laborious and currently applicable only to small volumes.

Recently, mapping of chemical synaptic connectivity has been aided by a variety of genetic methods for labeling synaptically connected neuronal pairs (Wickersham et al., 2007; Feinberg et al., 2008; Beier et al., 2011; Lo and Anderson, 2011). Parallel methods for mapping electrical synaptic connectivity could provide similar benefits. Recently, one such method was introduced, in which an esterase is targeted to specific cells; it acts on a membrane-permeable substrate to generate a fluorophore that can pass through gap junctions (Tian et al., 2012). Here, we report an alternative method, in which we use cre recombinase-dependent vectors to target a peptide transporter to the membrane of cre-expressing cells in vivo. We then incubated the tissue with a membrane-impermeable fluorophoreconjugated dipeptide that can, once inside the cell, pass through gap junctions from the transporter-expressing cell to electrically connected neighbors (Figure 1).

\section{RESULTS}

\section{Pept2 Mediates Labeling of Electrically Coupled Cells}

We used a human embryonic kidney cell line, HEK293, to test transporters and channels that would facilitate entry of membrane-impermeable but gap junction-permeable fluorescent molecules into cells. HEK cells have been reported to express connexin 43 and to form numerous gap junctions when grown as a confluent monolayer (Gemel et al., 2004; Johnson et al., 2013; Patel et al., 2014); we confirmed expression of connexin 43 immunohistochemically (Figure 2A) and we confirmed strong coupling by microinjection of neurobiotin, which is widely used to monitor coupling in tissue (Figure 2B).

We tested five protein/substrate pairs. Three were channels, TRPV1, TRPA1, and P2X7. All three are non-selective cation channels that are permeable to fluorescent molecules such as, Yo-pro-1 (TRPV1 and TRPA1) and ethidium (P2X7), (Meyers et al., 2003; Chen et al., 2009; Browne et al., 2013). We also tested the fluorescent dye Po-pro-1, which is closely related to Yo-pro-1. The other two proteins were related drug and peptide transporters, Pept1 and Pept2, both of which translocate the AMCA-labeled dipeptides beta-Ala-Lys ( $\beta$ ALA) and D-Ala-Lys (Dieck et al., 1999; Groneberg et al., 2001). Ethidium and Po-pro1 are known to cross gap junctions (Hoshi et al., 2006; Kanaporis et al., 2011) and we used microinjection to show that the same is true for $\beta$ ALA (Figure 2C).

In each case, we introduced the channel or transporter plus a fluorescent protein (XFP) by transfection into HEK293 cells, grew them for 1-2 days, then replated them with a 100-fold excess of unlabeled cells. The XFP was chosen to be distinguishable from the fluorophore to be tested. Once the cells reached confluency, we incubated them with the fluorophore. We activated TRPV1, TRPA1, and P2X7 by co-incubation with their ligands, capsaicin, allyl isothiocyanate (AITC) and ATP, respectively. We assessed uptake and transfer by observing substrate in XFP-labeled cells and neighboring XFP-negative cells, respectively (Figure 2D).

Signals in cells expressing TRPV1, TRPA1, and P2X7 channels were very dim and fluorophore was rarely detected in neighboring untransfected cells. In contrast, both Pept1 and Pept 2 supported robust uptake of $\beta A L A$, which was then transferred to neighboring cells. Of the two, Pept 2 was superior, perhaps reflecting its higher affinity (Daniel and Rubio-Aliaga, 2003; Zhang et al., 2004b; Biegel et al., 2006), (Figure 2E). Uptake was specific in that it was negligible in untransfected cells and was completely blocked by incubation with a 200 -fold excess of the competitive inhibitor, Glycine-Glutamine (GlyGln), (Figure 2F). We therefore used Pept2 for all subsequent studies reported here.

We generated two vectors to express both Pept 2 and GFP from a single transcript. In one, Pept2-GFP, we fused GFP directly to the C-terminal of Pept2. In the other, Pept2-p2a-GFP, the two proteins were separated by the self-cleaving $\mathrm{p} 2 \mathrm{a}$ sequence. When tested in HEK 293 cells as above, both constructs worked as efficiently as Pept 2 alone. In both cases, uptake was inhibited by Gly-Gln and transfer from GFP-expressing to GFP-negative cells was inhibited by carbenoxolone (CBX) and meclofenamic acid (MFA), two widely used gap junction blockers (Li et al., 2012; Yu et al., 2012) (Figures 3A,B).

\section{Quantitative Measurement of Gap Junction Strength}

To quantify the strength of gap junctional coupling, we developed an analysis based on the equation that describes the diffusion of $\beta A L A$ from the probe cell to the coupled cells (see Materials and Methods). We assume that the fluorescent intensity of $\beta$ ALA is proportional to the concentration of $\beta$ ALA. Therefore, at steady state, when the concentration of $\beta A L A$ in each cell no longer changes with time, the fluorescent signal of $\beta$ ALA from the probe cell to coupled cells follows an exponential decay (Figure 4A). We assayed diffusion patterns after $1,2,4$, and $6 \mathrm{~h}$ of incubation and found no obvious difference between those of 4 and $6 \mathrm{~h}$, suggesting that after $4 \mathrm{~h}$ of incubation, diffusion of $\beta$ ALA from the probe cell to the coupled cells was close to the steady state. Consistent with the result, the labeling pattern was well described by the diffusion equation following $4 \mathrm{~h}$ of incubation (Figure 4B).

To test the ability of this method to detect changes in coupling, we varied the concentration of the gap junction blockers, MFA and CBX. In both cases, the fluorescent intensity of $\beta$ ALA from the probe cell to coupled cells was well fitted by an exponential, with increasing concentrations of inhibitor leading to decreased diffusion and thus faster decay (Figures 4C-F). From each curve we estimated the decay constant and used it to derive coupling strength $\mathrm{S}$, which reflects how strongly two adjacent cells are coupled by gap junctions (Figures 4G,H). Coupling was nearly abolished by $10 \mu \mathrm{M}$ CBX and $40 \mu \mathrm{M}$ MFA.

\section{Pept2-Mediated Labeling of Electrically Coupled Retinal Neurons}

We chose mouse retina for tests in vivo, because it can be incubated with substrate as a thin, flat explant and 


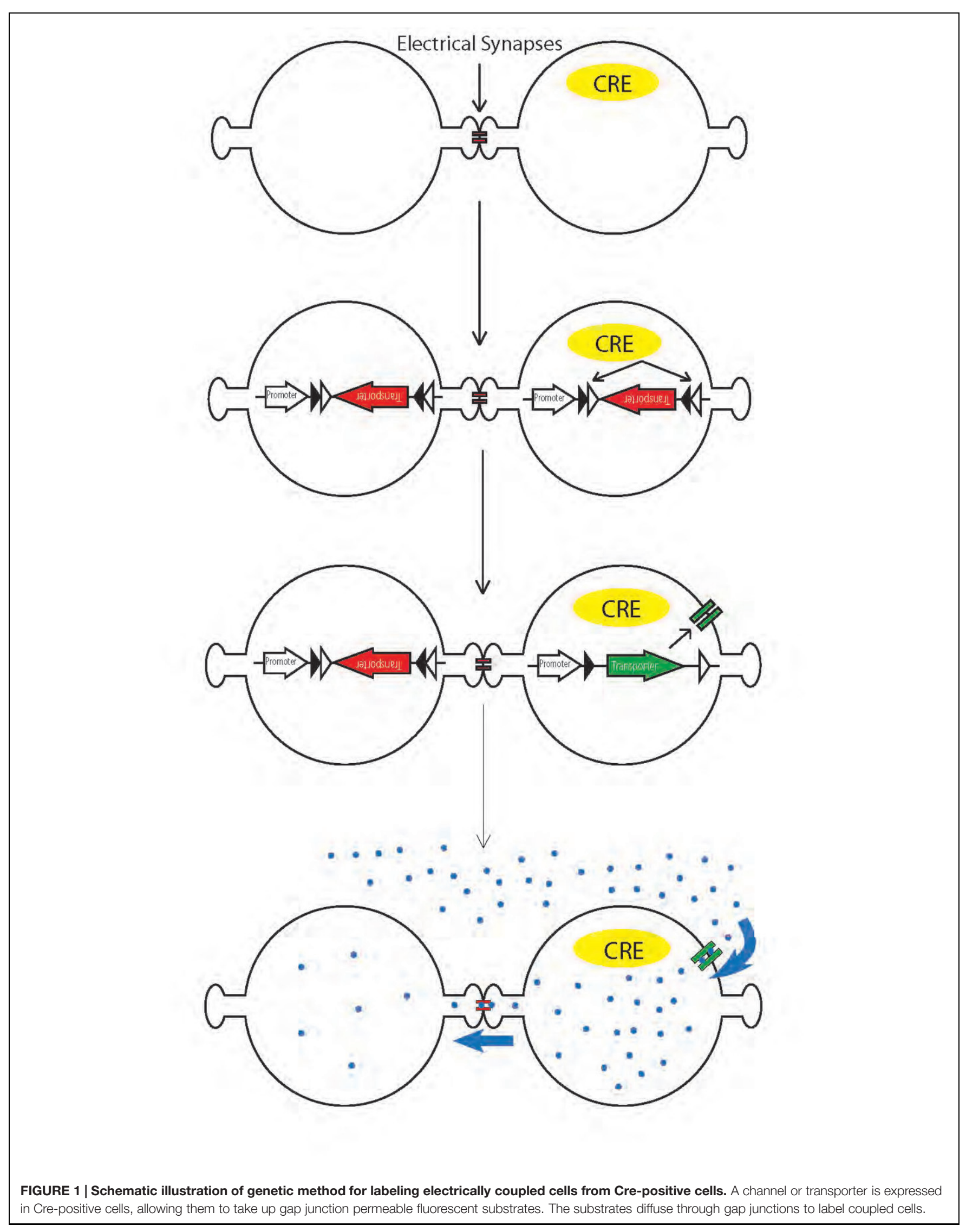


A

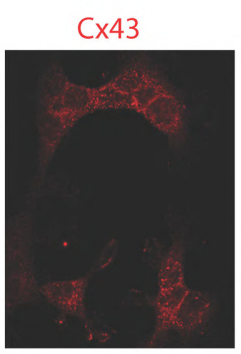

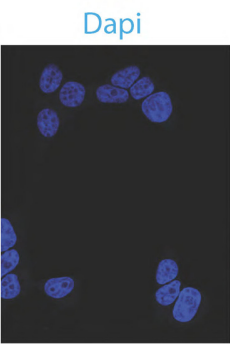

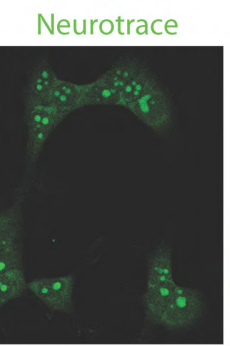

B

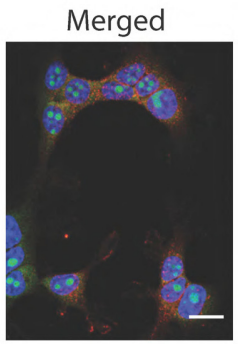

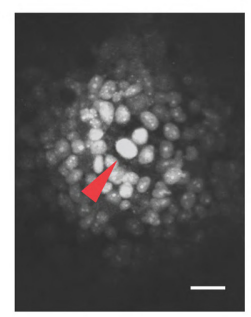

C

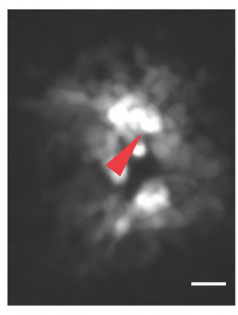

Transfect with:

1. CMV-Transporter/Channel + CMV-XFP

Replate with a 100 fold excess

2. CMV-Transporter/Channel-XFP or

of Untransfected cells

Incubate with

Fluorescent substrate CMV-Transporter/Channel-p2a-XFP

D

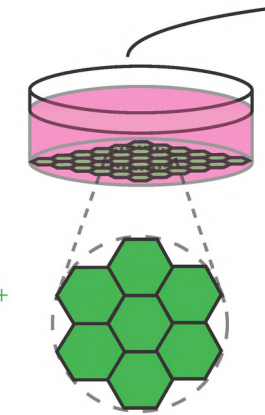

E

GFP

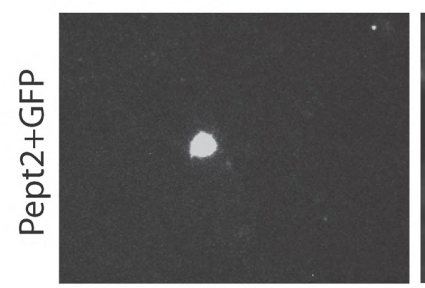

$\mathbf{F}$

Control
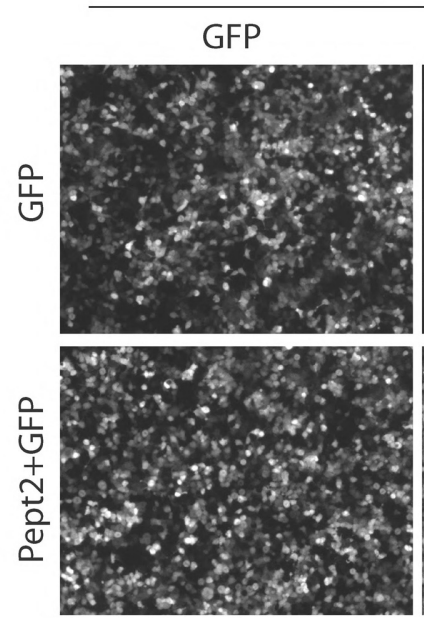

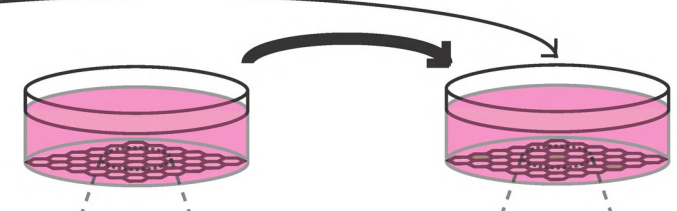

Untransfected

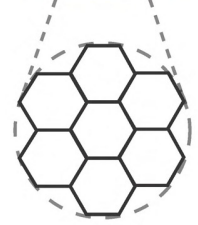

BALA
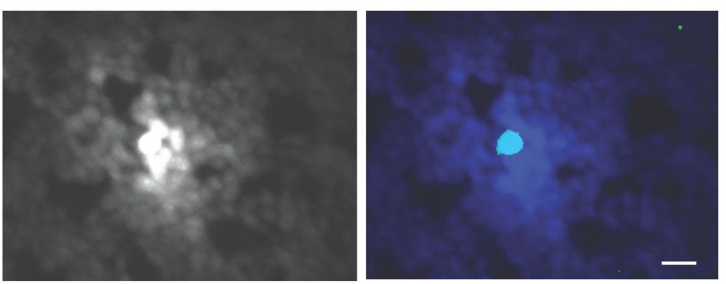

+Gly-Gln

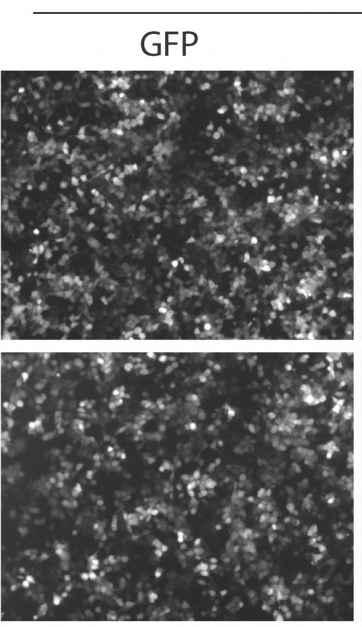

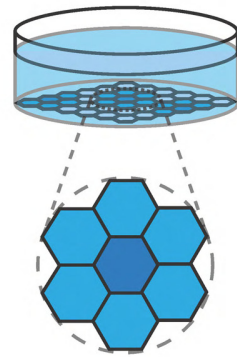

Bright Field
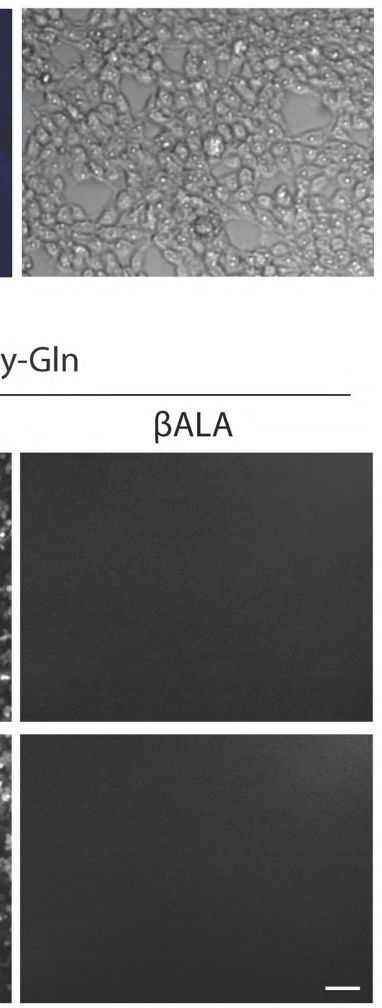


\section{FIGURE 2 | Continued}

Pept2 method enables labeling gap junction-coupled cells. (A) Cultured HEK cells stained with antibody against connexin 43 (Cx 43). Dapi shows cell nucleus and Neurotrace stains cytoplasm. Connexin 43 is enriched at the cell membrane between neighboring cells. (B) HEK cells injected with neurobiotin and stained with Texas red-streptavidin. Red arrow indicates the injected cell. (C) HEK cells injected with $\beta A L A$. Red arrow indicates the injected cell. (D) Schematic illustration of the method for testing channels or transporters capable of importing small fluorescent substrate that can permeate gap junctions. (E) HEK cells were transfected with GFP and Pept2, then mixed with a 100-fold excess of untransfected cells and incubated with $\beta A L A$. $\beta A L A$ diffused from GFP positive cells to adjacent coupled cells. (F) HEK cells were transfected with GFP, GFP + Pept2 or Pept2-GFP. Uptake of $\beta$ ALA was eliminated by Pept2 inhibitor Gly-Gln. Scale bars in (A-C,E): $20 \mu \mathrm{m}$; in (F): $100 \mu \mathrm{m}$.

because specific patterns of electrical coupling among its neurons have been mapped in detail (Bloomfield and Volgyi, 2009; Volgyi et al., 2009). Initial tests revealed, however, that BALA labeled a population of cells in wild-type retina, leading to signals that obscured some of the coupling we hoped to detect. Immunolabeling revealed that the labeled cells were predominantly Muller glia (glutamine synthetase and Sox9-positive; Supplementary Figure S1A), and uptake was abolished by co-incubation with Gly-Gln (Supplementary Figure S1B). These results suggested that Muller glia express pept2, which has been reported to be expressed by some glial populations in brain (Berger and Hediger, 1999; Dieck et al., 1999; Zimmermann and Stan, 2010). We therefore obtained targeted Pept2 null mutants (pept2 $2^{-/}$), which are viable and fertile (Shen et al., 2003). Uptake of $\beta$ ALA into Muller glia was abolished in retinas from pept $2^{-/-}$mice (Supplementary Figure S1C). No neural phenotypes have been reported for pept $2^{-/-}$(Shen et al., 2003) and we detected no changes in numbers, positions or arbors of any retinal cell types examined (Supplementary Figure S2). We therefore used pept $2^{-/-}$mice for studies in vivo.

To express Pept2 in cre-expressing neurons, we generated the adeno-associated virus (AAV) serotype 2, AAV-DiO-Pept2GFP in which a double-floxed inverted open-reading-frame (DiO) sequence renders expression of a Pept2-GFP fusion credependent (Figure 5A). To ensure that labeling was sparse, we used a mouse line in which one retinal ganglion cell (RGC) type,
A

B

\section{Pept2-GFP}
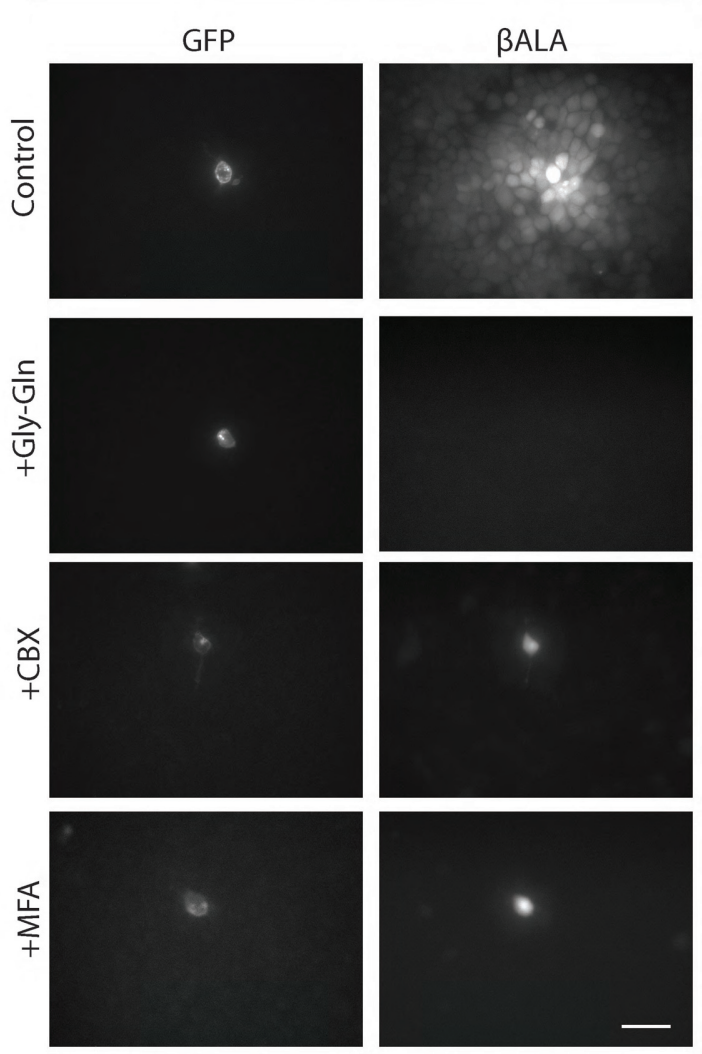
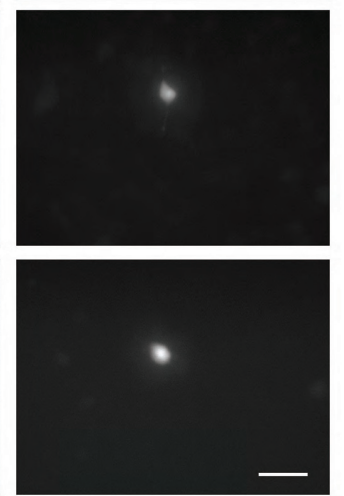

BALA
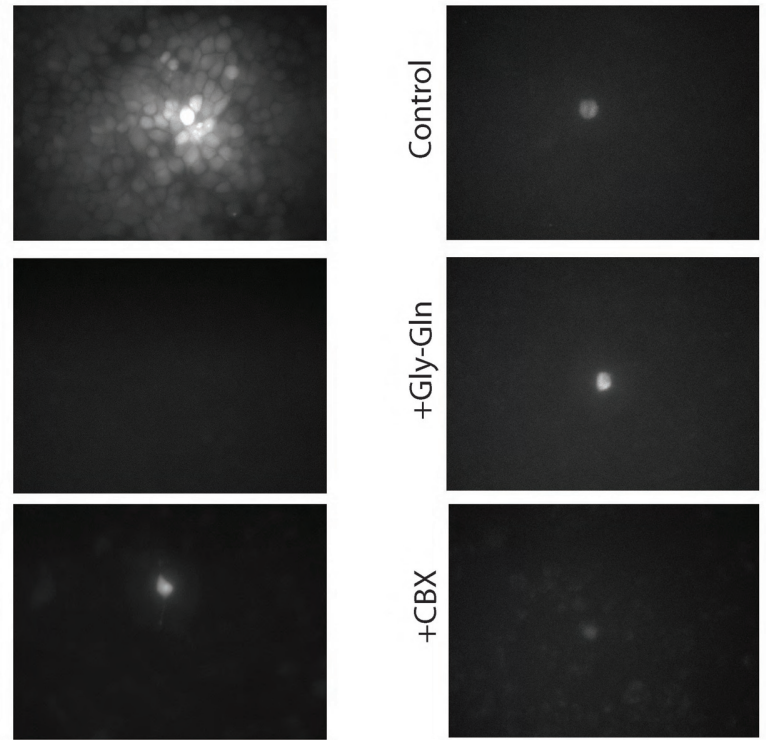

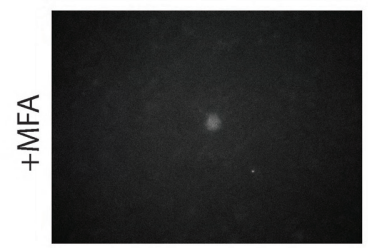

Pept2-p2a-GFP
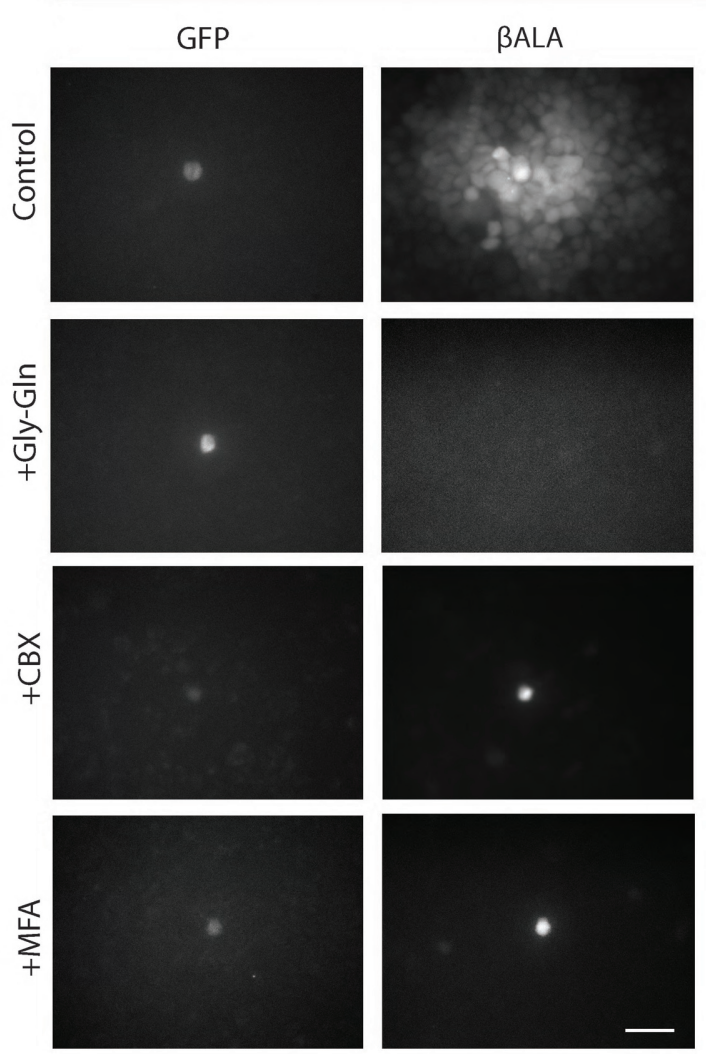

FIGURE 3 | Both Pept2-GFP and Pept2-p2a-GFP mediate $\beta$ ALA uptake. HEK cells were transfected with Pept2-GFP (A) or Pept2-p2a-GFP (B). Uptake of $\beta A L A$ was blocked by Pept2 inhibitor Gly-Gln. Diffusion of $\beta A L A$ to coupled cells was blocked by gap junction blockers MFA and CBX. Scale bar: $20 \mu \mathrm{m}$. 


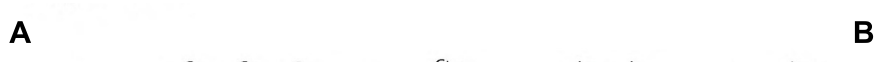

\section{B}
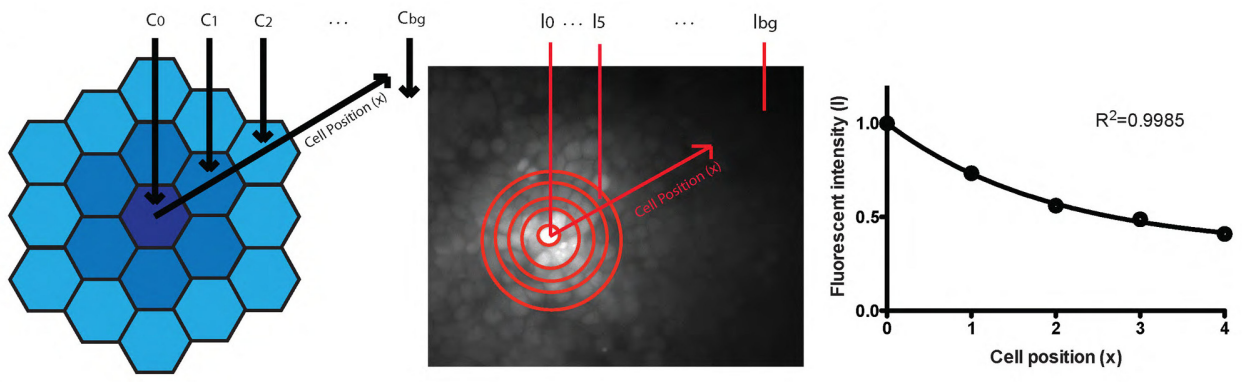

C

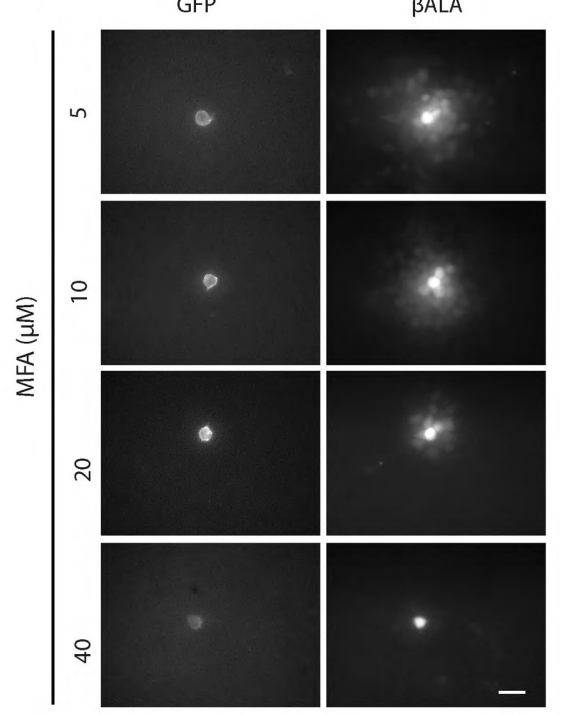

E

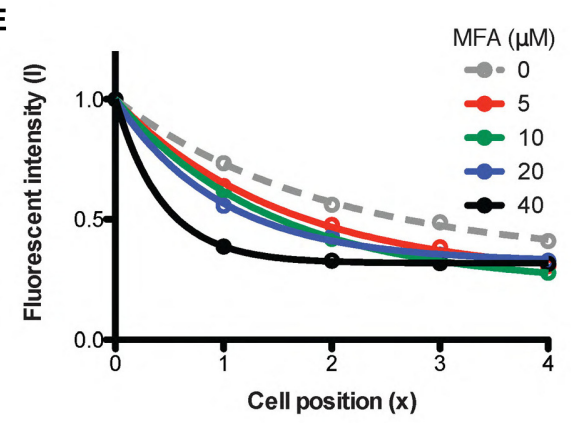

G

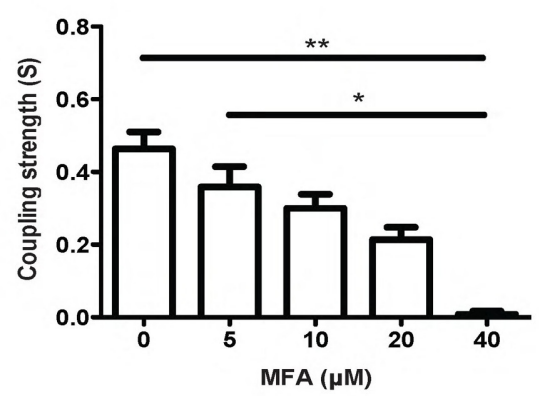

D

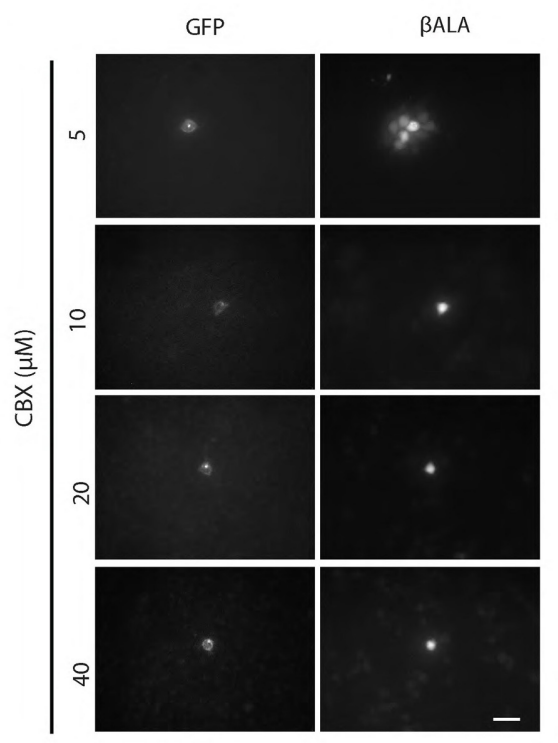

$\mathbf{F}$

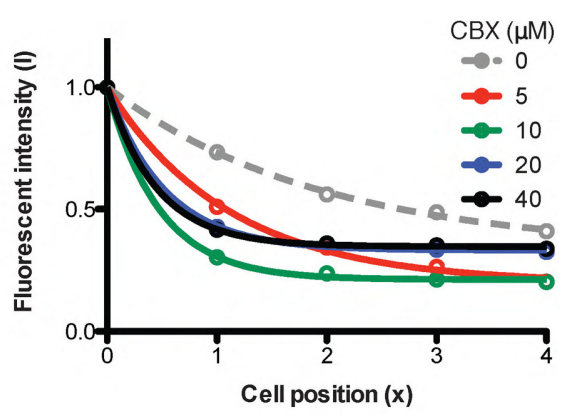

H

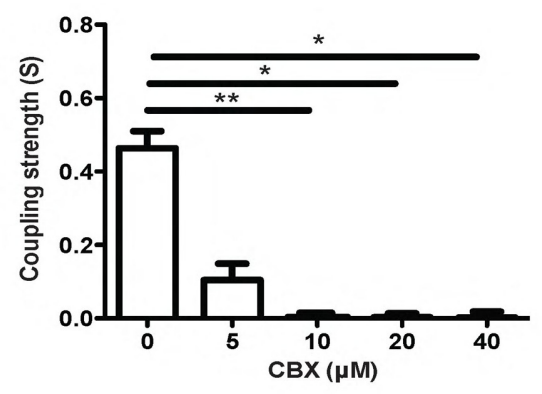




\section{FIGURE 4 | Continued}

Pept2 method enables quantification of gap junction strength between cultured cells. (A) Schematic illustration and measurement of the $\beta A L A$ signals for quantification of gap junction strength. (B) $\beta A L A$ signals from the probe cell to coupled cells follow an exponential decay. (C) Inhibition of $\beta A L A$ diffusion between gap junction-coupled cells by MFA at indicated concentrations. (D) Inhibition of $\beta A L A$ diffusion between gap junction-coupled cells by $\mathrm{CBX}$ at indicated concentrations.(E) Decay curves fitted from results in (C).(F) Decay curves fitted from results in (D). (G) Coupling strength $S$ calculated based on curves in (E). ${ }^{*} p<0.05 ;{ }^{* *} p<0.01, n=5$ probe cells for each condition. Error bars are SEM. (H) Coupling strength $S$ calculated based on (F). ${ }^{*} p<0.05 ;{ }^{* *} p<0.01, n=5$ probe cells for each condition. Error bars are SEM. Scale bars in (C,D): $20 \mu \mathrm{m}$

J-RGCs, express Cre fused with estrogen receptor [CreER; (Kim et al., 2008)]. In this line, recombinase activity is induced by tamoxifen in a dosage-dependent fashion. We infected mouse retina with high-titer AAV-DiO-Pept2-GFP and administered a low dose of tamoxifen 10 days later so that Pept 2 would be expressed in small numbers of J-RGCs.

GFP-expressing J-RGCs were readily recognizable by their strikingly asymmetric dendritic arbors (Figure 5B). Coupling partners of J-RGCs were amacrine cells in the inner nuclear layer (INL) but not other RGCs, consistent with coupling patterns of presumptive J-RGCs determined by microinjection (Hoshi and Mills, 2009; Volgyi et al., 2009). MFA (100 $\mu \mathrm{M})$ blocked transfer of $\beta$ ALA to the coupled amacrine cells (Figure 5C), indicting that $\beta A L A$ had been transferred from J-RGCs via electrical synapses. Thus, the Pept 2 method enables labeling of electrically coupled neurons in mouse retina.

We also introduced Pept 2 into horizontal cells, which are electrically coupled to each other in many species, including mice (Kaneko, 1971; Dacheux and Raviola, 1982; Mills and Massey, 1994; Bloomfield et al., 1995; Dacey, 1999; Dowling, 2012). For this purpose we injected AAV-DiO-Pept2-GFP subretinally into Sdk2-CreER; pept2-/- mice; Sdk2 is a synaptic recognition molecules that is expressed by horizontal cells as well as by specific populations of RGCs and amacrine cells (Krishnaswamy et al., 2015).

Probe (GFP-positive) cells were strongly labeled by $\beta$ ALA, and a set of neighboring cells were labeled less strongly. Both probe and coupled cells were identifiable as horizontal cells based on their size, shape, and mosaic arrangement (Figure 5D) and labeling with anti-calbindin (see below). As with J-RGCs, uptake by probe cells persisted but transfer was abolished in the presence of MFA $(100 \mu \mathrm{M})$, confirming that transfer reflected gap junctional coupling (Figure 5E). Together, these results demonstrate that the Pept 2 method can be used to detect electrically coupled neurons in vivo.

\section{Light-Dependent Electrical Coupling of Horizontal Cells}

The strength of horizontal cell coupling is modulated by light in several species, with coupling stronger in dark-adapted than in light-adapted retinas (Teranishi et al., 1983; Piccolino et al., 1984; Godley and Wurtman, 1988; Dong and McReynolds, 1991; Xin and Bloomfield, 1999; He et al., 2000; Zhang et al., 2011;
Dowling, 2012) Using the Pept2 method, we found that coupling strength is also light-dependent in mice: uptake of $\beta$ ALA into GFP-positive cells did not differ detectably between light- and dark-adapted retinas, but coupling strength was greater in the latter case (Figures 6A,B). Thus, electrical coupling of horizontal cells is modulated by illumination in mice as it is in other species.

The ability of the Pept 2 method to assay coupling of large numbers of cells over a large area allowed us to ask whether the effect of light-adaptation was local or whether it spread to dark-adapted regions of the same retina. For this purpose, we mounted dark-adapted Sdk2-CreER; pept $2^{-/}$retina infected with AAV-DiO-Pept2-GFP on a membrane filter with a small window in it, and placed it in a dish perfused with Ringer's solution. We illuminated the entire retina with a dim background light $\left(1 \mathrm{nW} / \mathrm{cm}^{2}\right)$ and shone a bright spot $\left(1 \mu \mathrm{W} / \mathrm{cm}^{2}\right)$ through the window region (Figure 6C). The membrane filter was opaque and the periphery of the dish was lightproof, so only the portion of the retina within the window was illuminated. Nonetheless, coupling was equivalent for cells inside the window (lightadapted) and outside the window (dark-adapted; Figure 6D). Similar results were obtained in six separate experiments, with the coupling midway between that observed for fully lightadapted and fully dark-adapted retinas (Figure 6E). This result suggests that electrical synaptic strength is modulated based on the 'averaged' light level across a broad expanse of retina instead of its local level.

We considered two alternative explanations for how the result in Figures 6D,E might have arisen. A trivial explanation is that light scattered from the window or penetrated the opaque filter to illuminate the nominally dark-adapted retina. The more interesting possibility is that long-distance lateral connections mediate the effect. To distinguish these alternatives, we made cuts between the portions of the retina that lay inside and outside the window before illuminating the central region. In this case, coupling of cells inside the window was low whereas coupling of cells outside the window was equivalent to that in fully darkadapted retina (Figures 6F,G). This result indicates that lateral connections lead to an equalization of coupling across the retina.

\section{DISCUSSION}

We developed a method for mapping electrical synaptic connections from genetically defined neurons based on a dipeptide transporter Pept 2 and its fluorescent substrate $\beta$ ALA. Using transfection and virus infection, we tested the Pept2 method in cultured cells and the retina. In both case, we observed coupling patterns consistent with those reported previously and quantified gap junction strength. We then used the method to analyze light-dependent modulation of electrical connectivity.

\section{Choice of Pept2}

We initially screened three channels, TRPV1, TRPA1, and P2X7, and two transporters, Pept1 and Pept2. In the cases of TRPV1, TRPA1, and P2X7, levels of fluorescent substrates in the transfected cells were low and electrically coupled cells were rarely detected. This observation could be explained in at least 
A

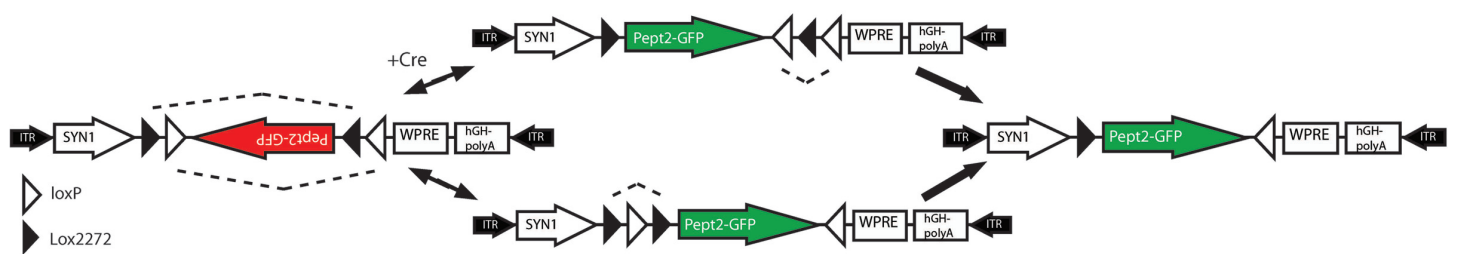

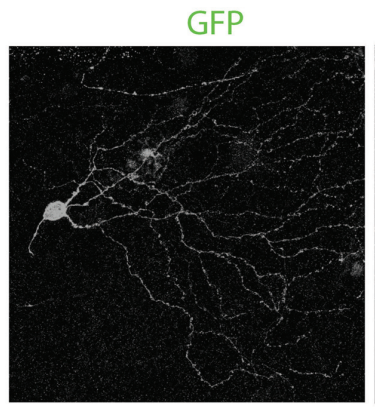

C

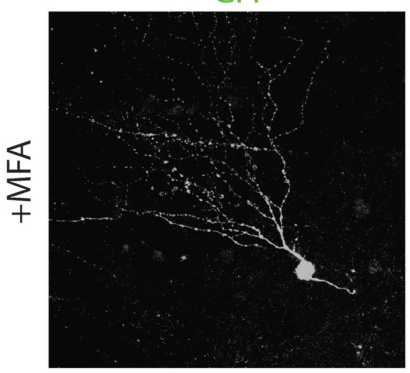

GFP

D

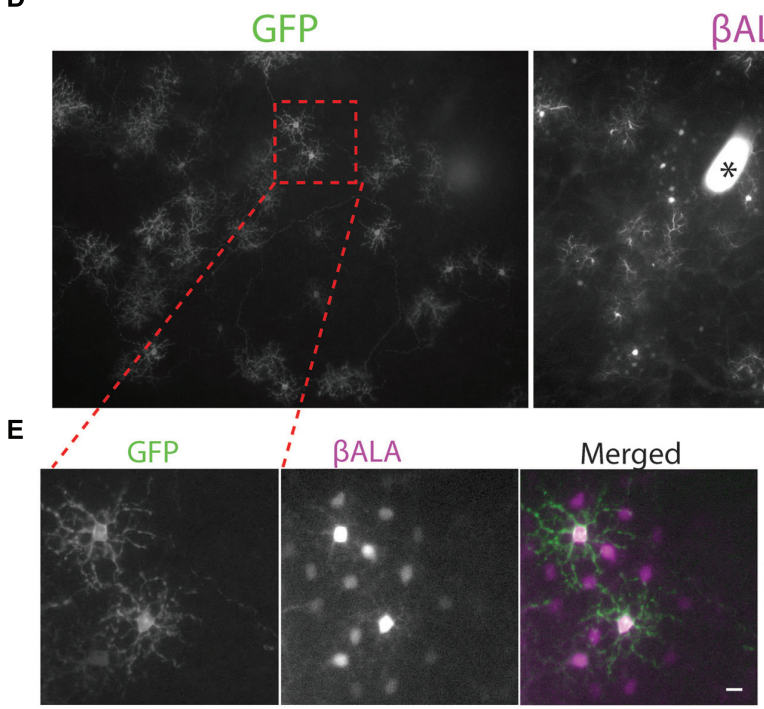

BALA (INL)

BALA (INL)
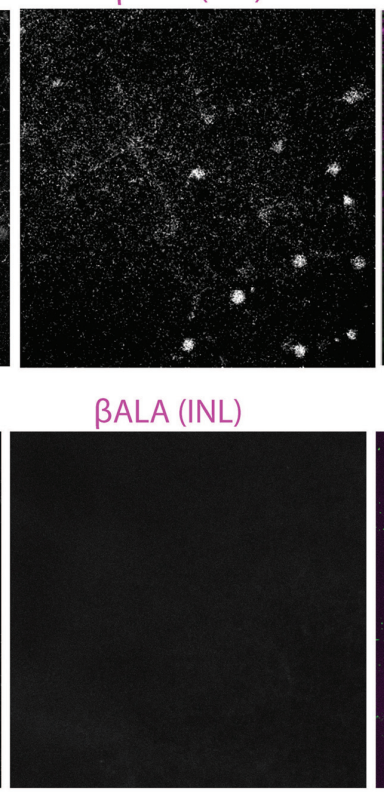

BALA
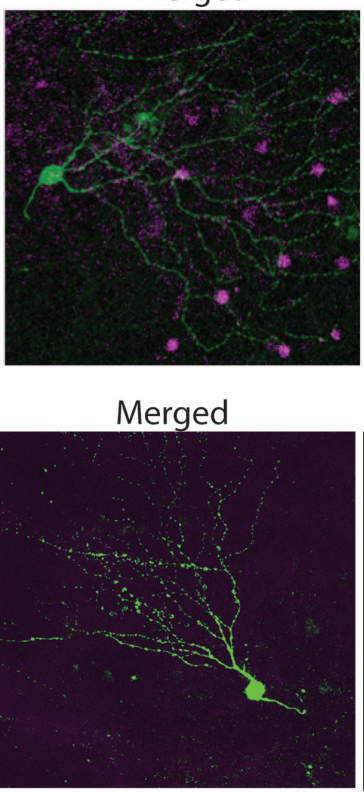

Merged

$\beta A L A(G C L)$

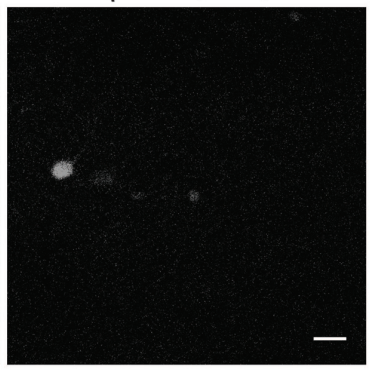

$\beta A L A(G C L)$

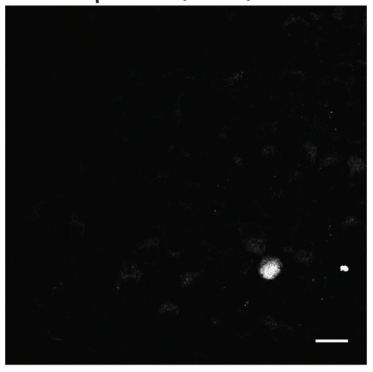

Merged

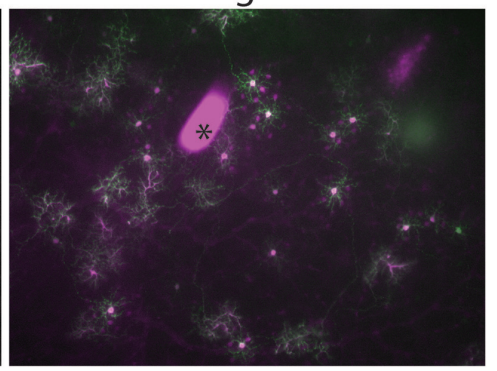

GFP
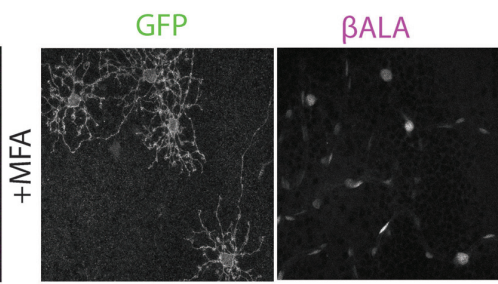

Merged

FIGURE 5 | Pept2 dependent method reveals coupled cells in the retina. (A) Schematic of Cre-dependent AAV carrying Pept2-GFP. (B) $\beta$ ALA signals were bright in Pept2-GFP positive J-RGCs in the ganglion cell layer (GCL), and also present in coupled amacrine cells in the INL. (C) Diffusion of $\beta A L A$ to coupled amacrine cells was eliminated by MFA. Scale bars in (B,C): $40 \mu \mathrm{m}$. (D) Pept2 method reveals coupling of horizontal cells. (E) Diffusion of $\beta A L A$ to coupled cells was eliminated by MFA. Scale bars in (D,E): $20 \mu \mathrm{m}$. Asterisk indicates a blot on the cover slide.

two ways: first, prolonged activation of these channels may lead to entry of large cations such as $\mathrm{Ca}^{2+}$, which can injure transfected cells (Jancsó et al., 1977; Meyers et al., 2003; Chen et al., 2009; Browne et al., 2013). We attempted to shorten the activation period or use a $\mathrm{Ca}^{2+}$ free incubation solution, but this had little effect. Alternatively, there is some evidence 


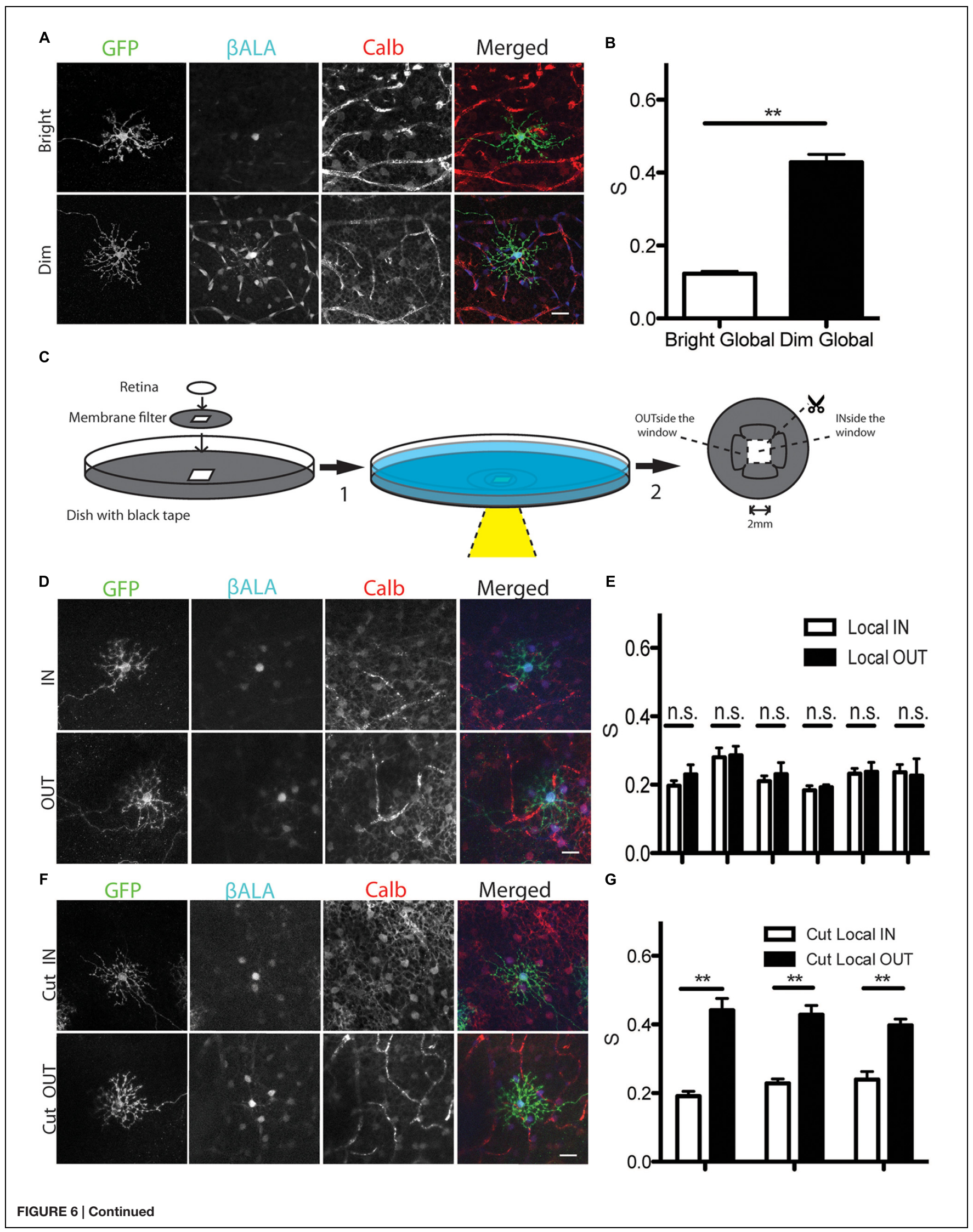




\section{FIGURE 6 | Continued}

Analysis of light dependent electrical coupling between horizontal cells. (A) Coupling between horizontal cells is stronger under dim light than under bright light. Horizontal cells are identified by the marker calbindin (Calb). Blood vessels are also stained by the secondary antibody against mouse Calb primary antibody, but can be easily distinguished from horizontal cells. (B) Quantification of electrical coupling strength $\mathrm{S}$ in (A). ${ }^{* *} p<0.01, n=73$ starter cells in bright light, $n=45$ starter cells in dim light. Error bars are SEM. (C) Schematic of assays to measure gap junction strength between horizontal cells under local stimulus in intact retina (step1 $\rightarrow$ step2). For cutting experiments, retinas were cut before incubation (step2 $\rightarrow$ step1). (D) Coupling strength of illuminated horizontal cells in a $\sim 4 \mathrm{~mm}^{2}$ window (IN) and those in an adjacent unilluminated region (OUT). (E) Quantification of gap junction strength from 6 separate retinas treated as in (D). $n=5-19$ starter cells for each condition per retina. Error bars are SEM. (F) Coupling strength of illuminated horizontal cells in a $\sim 4 \mathrm{~mm}^{2}$ window (Cut_IN) and those in an adjacent unilluminated region (Cut_OUT) from cut retina. (G) Quantification of gap junction strength from 3 separate retinas treated as in (F). $n=5-19$ starter cells for each condition per retina. Error bars are SEM. Scale bars in (A,D,E): $20 \mu \mathrm{m}$.

that the permeability of these channels to large cations requires activation of a secondary downstream pore (Bautista and Julius, 2008). In this case, introducing fluorophores into the transfected cells would require co-expression of the secondary channel or transporter, which may not have been present in the cells we tested.

In contrast, Pept 1 and Pept2, which transport di- and tripeptides and related drugs (Biegel et al., 2006; Newstead et al., 2011; Smith et al., 2013), were suitable for introduction of fluorophores into cells. Of the two, Pept 2 proved to be superior, likely because of its higher affinity: Pept 2 can bind and transport $\beta A L A$ into the cell efficiently even when the extracellular concentration is low. This low concentration of $\beta$ ALA causes lowlevel background, thus increases ratio of signal to noise (Daniel and Rubio-Aliaga, 2003; Zhang et al., 2004b; Biegel et al., 2006).

\section{Advantages of the Pept2 Method}

Pept2 is an oligopeptide-proton symporter. It functions as a secondary active transporter by direct coupling to $\mathrm{H}^{+}$-ATPase, or by indirect coupling to an ATPase through other transporters, for instance, coupling to a $\mathrm{Na}^{+} / \mathrm{H}^{+}$exchanger which in turn couples to a $\mathrm{Na}^{+} / \mathrm{K}^{+}$ATPase (Beyenbach and Wieczorek, 2006; Sala-Rabanal et al., 2008; Newstead et al., 2011; Smith et al., 2013). Active transport allows Pept 2 to transport $\beta$ ALA across the membrane against concentration gradient, allowing the intracellular concentration to reach a higher level than the extracellular concentration. Indeed, we observed brighter $\beta$ ALA signals in the transfected cells than in the bath solution. Once in the probe cell, $\beta$ ALA can diffuse readily through gap junctions as demonstrated by direct injection into HEK cells, cultured neurons and retinal neurons (Figure $\mathbf{1}$ and data not shown). Results from microinjection indicate that ideal fluorescent tracer for gap junction coupling should be small and positively charged (Mills and Massey, 1998; Kanaporis et al., 2011). $\beta A L A$ has a net charge of +1 , and a molecular weight of 432, comparable to 323 of Neurobiotin, a widely used tracer; and 579 of Po-pro-1, a recently reported tracer (Hoshi et al., 2006).
Compared with microinjection, the most widely used method for labeling electrically coupled neurons, the Pept 2 method has at least two advantages. First, expressing Pept2 by transfection or virus infection enables us to label multiple cells at once, whereas cells must be targeted one by one for microinjection. Second, microinjection requires impaling a target cell with an electrode, whereas the Pept 2 method is non-invasive, and maintains the integrity of the cell. Thus, the Pept 2 method allows study of electrical coupling from small or fragile cells deeply buried in tissue, which poses challenges for microinjection.

To quantify the strength of coupling measured with the Pept2 method, we used diffusion equations, based on the finding that spread of dye approached steady state following $4 \mathrm{~h}$ of incubation. Previous methods for assessing coupling strength were based on measurements of fluorescence intensity at different times after dye injection (Mills and Massey, 1998; Abbaci et al., 2008). These methods do not require that steady state be reached, but do require multiple measurements, which are infeasible in many circumstances.

\section{Limitations of the Pept2 Method}

Although the Pept 2 method has advantages, it is currently limited in some ways. First, endogenous Pept 2 is expressed by glial cells in the brain (Saito et al., 1996; Berger and Hediger, 1999; Dieck et al., 1999), and retina (Supplementary Figure S1). This endogenous Pept 2 expression led to background signals that obscured signals in labeled neurons. We therefore performed studies in pept $2^{-/-}$ mice so that probe cells and their electrically coupled cells could be visualized. This is obviously burdensome. Going forward, one could seek transporters that are not expressed in neuronal or glial cells, for instance, one derived from plants or fungi. Second, AMCA, the fluorophore used in this study, has low quantum yield compared with other fluorophores, such as fluorescein (Lavis and Raines, 2008). We used AMCA because $\beta$ ALA was commercially available. It should be possible, however, to synthesize the dipeptide conjugated to brighter fluorophores.

\section{Modulation of Electrical Coupling Between Horizontal Cells}

The Pept 2 method allowed us to study modulation of electrical coupling between neurons, a phenomenon that occurs in many neuronal circuits (Bargmann and Marder, 2013). Specifically, we analyzed light dependent modulation of electrical coupling between horizontal cells, which has been documented in several species (Teranishi et al., 1983; Piccolino et al., 1984; Godley and Wurtman, 1988; Dong and McReynolds, 1991; Xin and Bloomfield, 1999; He et al., 2000; Zhang et al., 2011; Dowling, 2012). A model for the role of modulation is as follows: In dim light, coupling is high, averaging signals from multiple photoreceptors and increasing the receptive field of the horizontal cells. This increase has the effect of enhancing the sensitivity of the retinal circuit at the expense of resolution. In bright light, coupling is decreased, sacrificing sensitivity for resolution (Masland, 2001; Bloomfield and Volgyi, 2009; Dowling, 2012). 
We confirmed that light also modulates coupling of horizontal cells in mouse retina, and then asked whether the modulation was confined to the illuminated area. We found that electrical coupling between horizontal cells was modulated based on the 'averaged' light level across a large area of retina. This contrastaveraged adaptation is different from conventional contrast adaptation at the photoreceptor level, which is local: only directly illuminated photoreceptors became less sensitive to light. This spatial restriction generates the afterimage (dark sensation) when eyes are moved away from a bright spot (Virsu, 1978). Thus, both local and global contrast adaptation exist in the mouse retina.

We speculate that long-distance modulation of electrical coupling between horizontal cells results from long-range lateral connections within the retina. Light dependent modulation is known to depend on dopamine: light leads to activation of dopaminergic amacrine cells in the retina, and causes dopamine release. Dopamine binds to dopaminergic receptors in horizontal cells and weakens the electrical coupling (Lasater, 1987; DeVries and Schwartz, 1989). Dopaminergic amacrine cells extend long processes that can span up to half of the whole retina (Zhang et al., 2004a). Thus, we suggest that processes of dopaminergic amacrine cells underlie the ability of the retina to average light over a large area.

In summary, the Pept 2 method provides a new tool for mapping electrical synaptic connectivity within neural circuits in the central nervous system. Combined with other techniques, such as functional imaging and gene profiling, it may also allow study of functional properties and molecular mechanism of electrical coupling.

\section{MATERIALS AND METHODS Animals}

JamB-CreER and Sdk2-CreER mice were generated in our lab and have been described previously (Kim et al., 2008; Krishnaswamy et al., 2015). JamB-CreER mice label J-RGCs, which are OFF-type direction selective RGCs responding to upward motion. Sdk2CreER mice label horizontal cells, as well as specific subtypes of amacrine cells and RGCs. pept $2^{-/-}$mice, in which endogenous pept2 expression was eliminated, were a kind gift from D. Smith (University of Michigan; Shen et al., 2003). Mice were maintained on a C57B6 background. All experiments were conducted in accordance with protocols approved by the Institutional Animal Care and Use Committees at Harvard University.

\section{Molecular Biology}

Using standard molecular cloning techniques, coding sequences of Pept1 (mouse), Pept2 (human), and P2X7 (mouse) were inserted downstream of the CMV promoter in the plasmid of pCMV-N1-EGFP to generate pCMV-Pept1, pCMV-Pept2, and pCMV-P2X7. Constructs of pCMV-TRPV1 and pCMV-TRPA1 were gifts from R. Gaudet (Harvard University).

pCMV-Pept2-GFP was generated by fusing the coding sequence of Pept2 (without STOP codon) to the $\mathrm{N}$ terminal of EGFP in the plasmid of pCMV-N1-EGFP. pCMV-Pept2p2a-GFP was generated by linking the coding sequence of Pept2 (without STOP codon) to EGFP using p2a sequence: 5'-
CGGAAGCGGAGCTACTAACTTCAGCCTGCTGAAGCAGGC TGGAGACGTGGAGGAGAACCCTGGACCTA-3’ (Kim et al., 2011).

Adeno-associated virus plasmid pAAV-hSyn1-DiO-WPRE was a kind gift from B. Lowell (Harvard Medical School). The Pept2-GFP sequence was cloned into this plasmid. The final vector was verified by sequencing and packaged in serotype 2 capsids following procedures described previously (Guo et al., 2012).

\section{Cell Culture}

HEK293 cells were seeded in 24-well plates and maintained in Dulbecco-modified Eagle's minimal essential medium supplemented with $10 \%$ fetal calf serum. Plasmids were transfected into $\sim 80 \%$ confluent HEK cells using lipofectamine 2000 reagent (Life Technology). Five hundred nanogram of the channel or transporter DNA together with $500 \mathrm{ng}$ pCMV-XFP DNA were transfected. For pCMV-Pept2-GFP and pCMV-Pept2-p2a-GFP, a total of 500 ng DNA was transfected.

After transfection, HEK cells were grown for another 1-2 days, and then dissociated by pipetting. Dissociated cells were mixed with untransfected HEK cells at a ratio of 1:100, replated in a 24well plate, and grown for another day.

The assay for uptake and transfer was based on procedures described previously (Dieck et al., 1999). After aspiration of the culture medium, HEK cells were washed twice and preincubated for $10 \mathrm{~min}$ with HEPES-buffered saline (HBS): $145 \mathrm{mM} \mathrm{NaCl}$, $5.4 \mathrm{mM} \mathrm{KCl}, 1.8 \mathrm{mM} \mathrm{CaCl}_{2}, 1 \mathrm{mM} \mathrm{MgCl}, 20 \mathrm{mM}$ HEPES, and $20 \mathrm{mM}$ glucose, $\mathrm{pH}=7.2$. The HBS was aspirated and the cells were incubated for $5 \mathrm{~min}-1 \mathrm{~h}$ for TRPV1, TRPA1, and P2X7 and 1-6 h for Pept 1 and Pept 2 with HBS containing fluorescent substrates. Substrate concentrations were: $100 \mu \mathrm{M}$ for Yo-pro-1 and Po-pro-1 (Life Technology), $100 \mu \mathrm{M}$ for Ethidium (Sigma) and $40 \mu \mathrm{M}$ for $\beta A L A$ (Biotrend). Capsaicin (1 $\mu \mathrm{M}$; Sigma), allyl isothiocyanate (300 $\mu \mathrm{M}$; Sigma) or ATP (5 mM, Sigma) were included to activate TRPV1, TRPA1, and P2X7 channels, respectively. After incubation, the cells were rapidly washed twice with ice-cold $\mathrm{HBS}$, and then fixed with $4 \%$ paraformaldehyde (PFA) at $4^{\circ} \mathrm{C}$ for $10 \mathrm{~min}$. Fixed cells were imaged using a Nikon inverted fluorescence microscope.

To test the specificity of Pept2-dependent uptake of $\beta A L A$, $8 \mathrm{mM}$ Gly-Gln was applied together with $40 \mu \mathrm{M} \beta \mathrm{ALA}$ for the incubation. To determine whether intercellular movement of $\beta A L A$ depended on gap junctions, HEK cells were preincubated with HBS containing $100 \mu \mathrm{M}$ CBX or MFA for $10 \mathrm{~min}$ before $\beta$ ALA was applied.

\section{Quantification of Gap Junction Strength from In Vitro Assays}

The diffusion of $\beta$ ALA from probe cells to coupled cells can be described by the following diffusion equations:

$$
\begin{gathered}
J(x, t)=-D \frac{\partial}{\partial x} C(x, t) \\
\frac{\partial}{\partial t} C(x, t)=-\frac{\partial}{\partial x} J(x, t)-k_{\text {out }} C(x, t)+k_{\text {in }} C_{\text {solution }}
\end{gathered}
$$


We define the probe cell as having position $x=0$, and number other cells by their distance from the probe cell. For example, cells directly coupled to the probe cell are designated $x=1$, cells coupled to directly coupled cells are designated $x=2$, cells coupled to $x=2$ cells are designated $x=3$ and so on (Figure 4A). $C(x, t)$ indicates the concentration of $\beta A L A$ in a cell at position $x$ at time $t$, and $C_{\text {solution }}$ is the concentration of BALA in the incubation solution. $\beta$ ALA was left in the extracellular solution throughout the diffusion step.

Equation 1 gives, at time point $t$, the amount of substrate that diffuses between adjacent cells is proportional to the concentration difference between the two cells. $D$ is the diffusion coefficient, $J(x, t)$ is the flow of $\beta$ ALA at cell at position $x$ at time $t$ with units of concentration per unit time, which measures the amount of BALA diffused from cell at position $x$ to adjacent cells $(x+1$ or $x-1)$ in a unit time.

Equation 2 describes change of substrate concentration in a cell at position $x$ at time $t$. This change has three sources, which are represented on the right side of the equation. The first is the flow of substrates from adjacent cells. Second, some $\beta A L A$ may be to the extracellular solution, for example through transporters such as multidrug resistant proteins. $k_{\text {out }}$ indicates the rate constant of this export. Third although $\beta$ ALA is a specific substrate for Pept transporters, a very small amount may enter the cell non-specifically. $k_{\text {in }}$ is the rate constant of this process.

Considering cells far away from the probe cells $(x \rightarrow \infty)$, these cells receive little flow of $\beta$ ALA $(J \rightarrow 0)$. Thus, when the concentration of $\beta$ ALA is steady in these cells $\left(\frac{\partial}{\partial t} C=0\right)$, based on Eq. (2), we have

$$
k_{\text {out }} C(x \rightarrow \infty)=k_{\text {in }} C_{\text {solution }}
$$

We define this $C(x \rightarrow \infty)$ as $C_{\mathrm{bg}}$.

At steady state when concentration of $\beta$ ALA in the cells doesn't change with time, we have

$$
\frac{\partial}{\partial t} C(x, t)=0
$$

Solving Eqs (1) and (2) at steady state, we get

$$
C(x)=\left(C_{0}-C_{b g}\right) e^{-\lambda x}+C_{b g}
$$

Where, $C_{0}$ is the concentration of $\beta$ ALA in the probe cell. Equation (5) has the form of an exponential decay, with decay constant

$$
\lambda=\sqrt{\frac{k_{\text {out }}}{D}}
$$

We assume the measured fluorescent intensity $(I)$ is proportional to the concentration $(C)$ of $\beta A L A$, and we get

$$
I(x)=\left(I_{0}-I_{b g}\right) e^{-\lambda x}+I_{b g}
$$

Normalizing fluorescent intensity to that of probe cell $I_{0}$, we get

$$
I_{\text {normalized }}(x)=\left(1-\frac{I_{b g}}{I_{0}}\right) e^{-\lambda x}+\frac{I_{b g}}{I_{0}}
$$

We fit data with this curve to get the decay constant $\lambda$.
Gap junction strength $S$ can then be defined as the proportion of substrate in the probe cell diffuses into the directly coupled cells:

$$
S=\frac{\left(C_{0}-C_{b g}\right) e^{-\lambda(x+1)}}{\left(C_{0}-C_{b g}\right) e^{-\lambda x}}=e^{-\lambda x}
$$

\section{Retinal Assays}

Using methods described previously, AAV-hSyn1-DiO-Pept2GFP was delivered subretinally (Samuel et al., 2014) to Sdk2CreER; pept $2^{-/-}$animals to label horizontal cells, and delivered intravitreally (Hong et al., 2011) to JamB-CreER; pept2 $2^{-/-}$ animals to label J-RGCs. For virus injection, adult animals were anesthetized by intraperitoneal injection of ketamine/xylazine. A $30^{1 / 2} \mathrm{G}$ needle was used to make a small hole in the temporal eye, below the cornea, and $2 \mu \mathrm{L}$ AAV-DiO-Pept2-GFP was injected with a Hamilton syringe and a $33 \mathrm{G}$ blunt-ended needle. Injected animals were euthanized and their retinas were dissected 4 weeks following injection.

Mice were dark adapted for at least $1 \mathrm{~h}$ prior to euthanasia. Retinas were dissected under infrared illumination in Mouse Ringers' solution ( $140 \mathrm{mM} \mathrm{NaCl}, 2.5 \mathrm{mM} \mathrm{KCl}, 2 \mathrm{mM} \mathrm{CaCl}$, $1 \mathrm{mM} \mathrm{MgCl} 2,22 \mathrm{mM} \mathrm{NaHCO}_{3}$, and $10 \mathrm{mM}$ glucose) oxygenated with $95 \% \mathrm{O}_{2}, 5 \% \mathrm{CO}_{2}$ at room temperature. The retina was then moved to a $6 \mathrm{~cm}$ petri dish perfused with oxygenated Mouse Ringers' at $32-34^{\circ} \mathrm{C}$. $\beta$ ALA was added to the Mouse Ringers' to a final concentration of $40 \mu \mathrm{M}$, and the incubation was continued for $\sim 4 \mathrm{~h}$. After incubation, the retina was rinsed twice with ice-cold oxygenated Mouse Ringers', and then fixed with $4 \% \mathrm{PFA}$ at $4^{\circ} \mathrm{C}$ for $30 \mathrm{~min}$. The retina was then processed for immunostaining and imaging.

To study light-dependent modulation of gap junction strength, a $\sim 2 \mathrm{~mm}$ aperture was cut into an opaque nitrocellulose filter (HABG01300, Millipore) and the dissected retina was mounted on the filter. The filter was then mounted into a lightproof $6 \mathrm{~cm}$ petri dish. Stimulation from a digital-lightprocessing projector (Dell) was focused onto the aperture. Stimulation intensity was $1 \mu \mathrm{W} / \mathrm{cm}^{2}$. Background light intensity was $1 \mathrm{nW} / \mathrm{cm}^{2}$. Thirty minutes after the onset of light stimulation, $\beta$ ALA was added to the Mouse Ringers'. After incubation, the retina with filter paper was rapidly washed twice with ice-cold oxygenated Mouse Ringers' and fixed with $4 \%$ PFA at $4^{\circ} \mathrm{C}$ for $30 \mathrm{~min}$. Following additional washes in PBS, the part of the retina within the aperture was separated from the rest by a sharp blade, and the two parts were processed for immunostaining and imaging.

To test whether the transfer of $\beta$ ALA was through gap junction, $100 \mu \mathrm{M}$ MFA was applied 10 min before adding $\beta A L A$.

\section{Immunohistochemistry}

Fixed retinas were either frozen and sectioned at $20 \mu \mathrm{m}$ in a cryostat or stained as whole mounts. Retina sections or whole mounts were incubated in PBS with 3\% donkey serum and 0.3\% Triton X-100 for blocking, followed by primary antibodies for $\geq 24 \mathrm{~h}$ at $4^{\circ} \mathrm{C}$ and secondary antibodies for $\sim 4 \mathrm{~h}$. Retinas were then washed with PBS and mounted in Fluoromount G (Southern Biotech). 
Primary antibodies used in this study were: rabbit anti-GFP (1:1000, Millipore); rabbit and mouse anticalbindin (1:2000, Swant and 1:100, Swant); goat anti-choline acetyltransferase (ChAT), (1:400, Millipore); mouse antiBrn3a (1:1000, Millipore); goat anti-Chx10 (1:200, Santa Cruz); mouse anti-AP2 (1:1000, DSHB); mouse anti-HCN4 (1: 1000, clone N114.10); rabbit anti-PKC alpha (1:1000, P4334 in Sigma); rabbit anti-secretagogin (1:4000, Biovendor); rabbit anti-arrestin (1:200, Milipore); rabbit anti-glutamine synthetase (1:1000, BD Biosciences); rabbit anti-sox9 (1:1000, Chemicon); mouse anti-connexin 43 (1:50, Life Sciences); rabbit antibody to Dab1 (a kind gift from B. Howell, SUNY Upstate Medical University). Secondary antibodies were conjugated to DyLight 649 (Jackson ImmunoResearch), Alexa Fluor 568, or Alexa Fluor 488 (Invitrogen) and used at $1: 500$.

\section{Imaging and Quantification of Signals}

Retinal images were taken with Zeiss LSM-710 confocal microscope using 405, 488, 568, and 647 lasers with a step size of $0.5 \mu \mathrm{m}$ and a $40 \mathrm{X}$ NA 1.3 lens. Images were then analyzed using Image $(\mathrm{NIH})$ software.

To quantify electrical synaptic strength between horizontal cells, the $\beta$ ALA signal in the starter GFP-positive horizontal cell was measured as $I_{0}$. Horizontal cells surrounding this cell were identified by immunostaining for the marker calbindin. Because horizontal cells form a mosaic in mouse retina, we took the six horizontal cells that were closest to the starter cell as directly coupled cells, and measured $\beta$ ALA signals in them as $I_{1}$. The electrical synaptic strength $S$ was defined as the proportion of substrate in the starter cell diffuses into the directly coupled cells. Adjusting for the background signals, we calculated the electrical synaptic strength as following:

$$
S=\frac{\text { Averaged } I_{1}-I_{b g}}{I_{0}-I_{b g}}
$$

\section{REFERENCES}

Abbaci, M., Barberi-Heyob, M., Blondel, W., Guillemin, F., and Didelon, J. (2008). Advantages and limitations of commonly used methods to assay the molecular permeability of gap junctional intercellular communication. Biotechniques 45, 56-62. doi: 10.2144/000 112810

Apostolides, P. F., and Trussell, L. O. (2013). Regulation of interneuron excitability by gap junction coupling with principal cells. Nat. Neurosci. 16, 1764-1772. doi: 10.1038/nn.3569

Bargmann, C. I., and Marder, E. (2013). From the connectome to brain function. Nat. Methods 10, 483-490. doi: 10.1038/nmeth.2451

Bautista, D., and Julius, D. (2008). Fire in the hole: pore dilation of the capsaicin receptor TRPV1. Nat. Neurosci. 11, 528-529. doi: 10.1038/nn0508-528

Beier, K. T., Saunders, A., Oldenburg, I. A., Miyamichi, K., Akhtar, N., Luo, L., et al. (2011). Anterograde or retrograde transsynaptic labeling of CNS neurons with vesicular stomatitis virus vectors. Proc. Natl. Acad. Sci. U.S.A. 108, 15414-15419. doi: 10.1073/pnas.11108 54108

Berger, U. V., and Hediger, M. A. (1999). Distribution of peptide transporter PEPT2 mRNA in the rat nervous system. Anat. Embryol. (Berl.) 199, 439-449. doi: $10.1007 / \mathrm{s} 004290050242$

\section{AUTHOR CONTRIBUTIONS}

MQ and JRS conceived the project, designed experiments, and wrote the manuscript. MQ performed experiments and analyzed data.

\section{ACKNOWLEDGMENTS}

We thank Sanes lab members for useful discussion and comments on this work, Monica Sala-Rabanal (Washington University of Saint Louis) for Pept2 cDNA, Rachelle Gaudet (Harvard University) for pCMV-TRPV1 and pCMV-TRPA1 plasmids, Brad Lowell (Harvard Medical School) for the AAV plasmid, and Brian Howell for Dab1 antibody. This work is supported by grant NS029169 to JRS.

\section{SUPPLEMENTARY MATERIAL}

The Supplementary Material for this article can be found online at: http://journal.frontiersin.org/article/10.3389/fnmol. 2015.00081

FIGURE S1 | Muller glial cells express endogenous pept2 and take $\beta A L A$. (A-C) $\beta A L A$ uptake in wild type retina (A), wild type retina treated with Gly-Gln (B) and pept $2^{-/}$-retina (C). Sections were stained with antibody to glutamine synthetase and sox 9, which are molecular markers for Muller glia cells. Scale bar: $20 \mu \mathrm{m}$.

FIGURE S2 | Normal retinal architecture in pept2-/- animals. Sections of pept $2^{-/-}$retinas stained with antibodies to cell-type specific markers. No differences between wild type and pept2 ${ }^{-/-}$retinas were detected: Brn3a labels most RGCs; AP2 labels all amacrine cells; Chx10 labels all bipolar cells; Anti-ChAT labels somas and dendrites of starburst amacrine cells; Anti-protein kinase C (PKC) labels rod bipolar cells and a small subset of amacrine cells; Anti-disabled (DAB) labels All amacrines; Anti-Secretagogin labels subsets of bipolar cells; Anti-calbindin labels horizontal cells, subsets of RGCs and amacrine cells, including starburst amacrine cells; Anti-HCN4 labels type 3a bipolar cells; Anti-Arrestin labels cone photoreceptors. Scale bar: $20 \mu \mathrm{m}$.

Beyenbach, K. W., and Wieczorek, H. (2006). The V-type H+ ATPase: molecular structure and function, physiological roles and regulation. J. Exp. Biol. 209, 577-589. doi: 10.1242/jeb.02014

Biegel, A., Knutter, I., Hartrodt, B., Gebauer, S., Theis, S., Luckner, P., et al. (2006). The renal type $\mathrm{H}+/$ peptide symporter PEPT2: structureaffinity relationships. Amino Acids 31, 137-156. doi: 10.1007/s00726-0060331-0

Bloomfield, S. A., and Volgyi, B. (2009). The diverse functional roles and regulation of neuronal gap junctions in the retina. Nat. Rev. Neurosci. 10, 495-506. doi: $10.1038 / \mathrm{nrn} 2636$

Bloomfield, S. A., Xin, D., and Persky, S. E. (1995). A comparison of receptive field and tracer coupling size of horizontal cells in the rabbit retina. Vis. Neurosci. 12, 985-999. doi: 10.1017/S0952523800009524

Browne, L. E., Compan, V., Bragg, L., and North, R. A. (2013). P2X7 receptor channels allow direct permeation of nanometer-sized dyes. J. Neurosci. 33, 3557-3566. doi: 10.1523/JNEUROSCI.2235-12.2013

Chen, J., Kim, D., Bianchi, B. R., Cavanaugh, E. J., Faltynek, C. R., Kym, P. R., et al. (2009). Pore dilation occurs in TRPA1 but not in TRPM8 channels. Mol. Pain 5:3. doi: 10.1186/1744-8069-5-3

Connors, B. W., and Long, M. A. (2004). Electrical synapses in the mammalian brain. Annu. Rev. Neurosci. 27, 393-418. doi: 10.1146/annurev.neuro.26.041002.131128 
Cook, J. E., and Becker, D. L. (2009). Gap-junction proteins in retinal development: new roles for the "nexus." Physiology (Bethesda) 24, 219-230. doi: 10.1152/physiol.00007.2009

Dacey, D. M. (1999). Primate retina: cell types, circuits and color opponency. Prog. Retin. Eye Res. 18, 737-763. doi: 10.1016/S1350-9462(98)00013-5

Dacheux, R. F., and Raviola, E. (1982). Horizontal cells in the retina of the rabbit. J. Neurosci. 2, 1486-1493.

Daniel, H., and Rubio-Aliaga, I. (2003). An update on renal peptide transporters. Am. J. Physiol. Renal Physiol. 284, F885-F892. doi: 10.1152/ajprenal.00123.2002

DeVries, S. H., and Schwartz, E. A. (1989). Modulation of an electrical synapse between solitary pairs of catfish horizontal cells by dopamine and second messengers. J. Physiol. 414, 351-375. doi: 10.1113/jphysiol.1989.sp017692

Dieck, S. T., Heuer, H., Ehrchen, J., Otto, C., and Bauer, K. (1999). The peptide transporter PepT2 is expressed in rat brain and mediates the accumulation of the fluorescent dipeptide derivative beta-Ala-Lys-NepsilonAMCA in astrocytes. Glia 25, 10-20.

Dong, C. J., and McReynolds, J. S. (1991). The relationship between light, dopamine release and horizontal cell coupling in the mudpuppy retina. J. Physiol. 440, 291-309. doi: 10.1113/jphysiol.1991.sp018709

Dowling, J. E. (2012). The Retina: An Approachable Part of the Brain. Cambridge, MA: Belknap Press of Harvard University Press.

Feinberg, E. H., Vanhoven, M. K., Bendesky, A., Wang, G., Fetter, R. D., Shen, K., et al. (2008). GFP Reconstitution Across Synaptic Partners (GRASP) defines cell contacts and synapses in living nervous systems. Neuron 57, 353-363. doi: 10.1016/j.neuron.2007.11.030

Gemel, J., Valiunas, V., Brink, P. R., and Beyer, E. C. (2004). Connexin43 and connexin26 form gap junctions, but not heteromeric channels in co-expressing cells. J. Cell Sci. 117, 2469-2480. doi: 10.1242/jcs.01084

Godley, B. F., and Wurtman, R. J. (1988). Release of endogenous dopamine from the superfused rabbit retina in vitro: effect of light stimulation. Brain Res. 452, 393-395. doi: 10.1016/0006-8993(88)90046-7

Groneberg, D. A., Doring, F., Eynott, P. R., Fischer, A., and Daniel, H. (2001). Intestinal peptide transport: ex vivo uptake studies and localization of peptide carrier PEPT1. Am. J. Physiol. Gastrointest. Liver Physiol. 281, G697-G704.

Guo, P., El-Gohary, Y., Prasadan, K., Shiota, C., Xiao, X., Wiersch, J., et al. (2012). Rapid and simplified purification of recombinant adeno-associated virus. J. Virol. Methods 183, 139-146. doi: 10.1016/j.jviromet.2012.04.004

He, S., Weiler, R., and Vaney, D. I. (2000). Endogenous dopaminergic regulation of horizontal cell coupling in the mammalian retina. J. Comp. Neurol. 418, 33-40. doi: 10.1002/(SICI)1096-9861(20000228)418:1 <33::AID-CNE3>3.0.CO;2-J

Hong, Y. K., Kim, I. J., and Sanes, J. R. (2011). Stereotyped axonal arbors of retinal ganglion cell subsets in the mouse superior colliculus. J. Comp. Neurol. 519, 1691-1711. doi: 10.1002/cne.22595

Hormuzdi, S. G., Filippov, M. A., Mitropoulou, G., Monyer, H., and Bruzzone, R. (2004). Electrical synapses: a dynamic signaling system that shapes the activity of neuronal networks. Biochim. Biophys. Acta 1662, 113-137. doi: 10.1016/j.bbamem.2003.10.023

Hoshi, H., and Mills, S. L. (2009). Components and properties of the G3 ganglion cell circuit in the rabbit retina. J. Comp. Neurol. 513, 69-82. doi: $10.1002 /$ cne. 21941

Hoshi, H., O’Brien, J., and Mills, S. L. (2006). A novel fluorescent tracer for visualizing coupled cells in neural circuits of living tissue. J. Histochem. Cytochem. 54, 1169-1176. doi: 10.1369/jhc.6A6935.2006

Jancsó, G., Kiraly, E., and Jancsó-Gábor, A. (1977). Pharmacologically induced selective degeneration of chemosensitive primary sensory neurones. Nature 270, 741-743. doi: 10.1038/270741a0

Johnson, K. E., Mitra, S., Katoch, P., Kelsey, L. S., Johnson, K. R., and Mehta, P. P. (2013). Phosphorylation on Ser-279 and Ser-282 of connexin43 regulates endocytosis and gap junction assembly in pancreatic cancer cells. Mol. Biol. Cell 24, 715-733. doi: 10.1091/mbc.E12-07-0537

Kanaporis, G., Brink, P. R., and Valiunas, V. (2011). Gap junction permeability: selectivity for anionic and cationic probes. Am. J. Physiol. Cell Physiol. 300, C600-C609. doi: 10.1152/ajpcell.00316.2010

Kaneko, A. (1971). Electrical connexions between horizontal cells in the dogfish retina. J. Physiol. 213, 95-105. doi: 10.1113/jphysiol.1971.sp009370

Kim, I. J., Zhang, Y., Yamagata, M., Meister, M., and Sanes, J. R. (2008). Molecular identification of a retinal cell type that responds to upward motion. Nature 452, 478-482. doi: 10.1038/nature06739
Kim, J. H., Lee, S. R., Li, L. H., Park, H. J., Park, J. H., Lee, K. Y., et al. (2011). High cleavage efficiency of a $2 \mathrm{~A}$ peptide derived from porcine teschovirus-1 in human cell lines, zebrafish and mice. PLoS ONE 6:e18556. doi: 10.1371/journal.pone.0018556

Krishnaswamy, A., Yamagata, M., Duan, X., Hong, Y. K., and Sanes, J. R. (2015). Sidekick 2 directs formation of a retinal circuit that detects differential motion. Nature 524, 466-470. doi: 10.1038/nature14682

Lasater, E. M. (1987). Retinal horizontal cell gap junctional conductance is modulated by dopamine through a cyclic AMP-dependent protein kinase. Proc. Natl. Acad. Sci. U.S.A. 84, 7319-7323. doi: 10.1073/pnas.84.20.7319

Lavis, L. D., and Raines, R. T. (2008). Bright ideas for chemical biology. ACS Chem. Biol. 3, 142-155. doi: 10.1021/cb700248m

Li, Y., Lu, H., Cheng, P. L., Ge, S., Xu, H., Shi, S. H., et al. (2012). Clonally related visual cortical neurons show similar stimulus feature selectivity. Nature 486, 118-121. doi: 10.1038/nature11110

Lo, L., and Anderson, D. J. (2011). A Cre-dependent, anterograde transsynaptic viral tracer for mapping output pathways of genetically marked neurons. Neuron 72, 938-950. doi: 10.1016/j.neuron.2011.12.002

Masland, R. H. (2001). The fundamental plan of the retina. Nat. Neurosci. 4, 877-886. doi: 10.1038/nn0901-877

Meyers, J. R., Macdonald, R. B., Duggan, A., Lenzi, D., Standaert, D. G., Corwin, J. T., et al. (2003). Lighting up the senses: FM1-43 loading of sensory cells through nonselective ion channels. J. Neurosci. 23, 4054-4065.

Mills, S. L., and Massey, S. C. (1994). Distribution and coverage of A- and B-type horizontal cells stained with Neurobiotin in the rabbit retina. Vis. Neurosci. 11, 549-560. doi: 10.1017/S0952523800002455

Mills, S. L., and Massey, S. C. (1998). The kinetics of tracer movement through homologous gap junctions in the rabbit retina. Vis. Neurosci. 15, 765-777. doi: $10.1017 /$ S0952523898154159

Newstead, S., Drew, D., Cameron, A. D., Postis, V. L., Xia, X., Fowler, P. W., et al. (2011). Crystal structure of a prokaryotic homologue of the mammalian oligopeptide-proton symporters, PepT1 and PepT2. EMBO J. 30, 417-426. doi: 10.1038/emboj.2010.309

Patel, D., Zhang, X., and Veenstra, R. D. (2014). Connexin hemichannel and pannexin channel electrophysiology: how do they differ? FEBS Lett. 588, 13721378. doi: 10.1016/j.febslet.2013.12.023

Piccolino, M., Neyton, J., and Gerschenfeld, H. M. (1984). Decrease of gap junction permeability induced by dopamine and cyclic adenosine $3^{\prime}: 5^{\prime}$-monophosphate in horizontal cells of turtle retina. J. Neurosci. 4, 2477-2488.

Saito, H., Terada, T., Okuda, M., Sasaki, S., and Inui, K. (1996). Molecular cloning and tissue distribution of rat peptide transporter PEPT2. Biochim. Biophys. Acta 1280, 173-177. doi: 10.1016/0005-2736(96)00024-7

Sala-Rabanal, M., Loo, D. D., Hirayama, B. A., and Wright, E. M. (2008). Molecular mechanism of dipeptide and drug transport by the human renal H+/oligopeptide cotransporter hPEPT2. Am. J. Physiol. Renal Physiol. 294, F1422-F1432. doi: 10.1152/ajprenal.00030.2008

Samuel, M. A., Voinescu, P. E., Lilley, B. N., De Cabo, R., Foretz, M., Viollet, B., et al. (2014). LKB1 and AMPK regulate synaptic remodeling in old age. Nat. Neurosci. 17, 1190-1197. doi: 10.1038/nn.3772

Sanes, J. R., and Yamagata, M. (2009). Many paths to synaptic specificity. Annu. Rev. Cell Dev. Biol. 25, 161-195. doi: 10.1146/annurev.cellbio.24.110707. 175402

Shen, H., Smith, D. E., Keep, R. F., Xiang, J., and Brosius, F. C. 3rd (2003). Targeted disruption of the PEPT2 gene markedly reduces dipeptide uptake in choroid plexus. J. Biol. Chem. 278, 4786-4791. doi: 10.1074/jbc.M207397200

Siegelbaum, S. A., and Kandel, E. R. (2013). “Overview of synaptic transmission," in Principles of Neural Science, 5th Edn, eds E. R. Kandel, J. H. Schwartz, T. M. Jessell, S. A. Siegelbaum, and A. J. Hudspeth (New York, NY: McGraw-Hill), $177-188$.

Smith, D. E., Clemencon, B., and Hediger, M. A. (2013). Proton-coupled oligopeptide transporter family SLC15: physiological, pharmacological and pathological implications. Mol. Aspects Med. 34, 323-336. doi: 10.1016/j.mam.2012.11.003

Teranishi, T., Negishi, K., and Kato, S. (1983). Dopamine modulates S-potential amplitude and dye-coupling between external horizontal cells in carp retina. Nature 301, 243-246. doi: 10.1038/301243a0

Tian, L., Yang, Y., Wysocki, L. M., Arnold, A. C., Hu, A., Ravichandran, B., et al. (2012). Selective esterase-ester pair for targeting small molecules 
with cellular specificity. Proc. Natl. Acad. Sci. U.S.A. 109, 4756-4761. doi: 10.1073/pnas.1111943109

Vaney, D. I. (1991). Many diverse types of retinal neurons show tracer coupling when injected with biocytin or Neurobiotin. Neurosci. Lett. 125, 187-190. doi: 10.1016/0304-3940(91)90024-N

Varshney, L. R., Chen, B. L., Paniagua, E., Hall, D. H., and Chklovskii, D. B. (2011). Structural properties of the Caenorhabditis elegans neuronal network. PLoS Comput. Biol. 7:e1001066. doi: 10.1371/journal.pcbi.1001066

Virsu, V. (1978). Retinal mechanisms of visual adaptation and afterimages. Med. Biol. 56, 84-96.

Volgyi, B., Chheda, S., and Bloomfield, S. A. (2009). Tracer coupling patterns of the ganglion cell subtypes in the mouse retina. J. Comp. Neurol. 512, 664-687. doi: $10.1002 /$ cne.21912

White, J. G., Southgate, E., Thomson, J. N., and Brenner, S. (1986). The structure of the nervous system of the nematode Caenorhabditis elegans. Philos. Trans. $R$. Soc. Lond. B Biol. Sci. 314, 1-340. doi: 10.1098/rstb.1986.0056

Wickersham, I. R., Lyon, D. C., Barnard, R. J., Mori, T., Finke, S., Conzelmann, K. K., et al. (2007). Monosynaptic restriction of transsynaptic tracing from single, genetically targeted neurons. Neuron 53, 639-647. doi: 10.1016/j.neuron.2007.01.033

Xin, D., and Bloomfield, S. A. (1999). Dark- and light-induced changes in coupling between horizontal cells in mammalian retina. J. Comp. Neurol. 405, 75-87. doi: 10.1002/(SICI) 1096-9861(19990301)405:1 < 75::AID-CNE6> 3.0.CO;2-D

Yogev, S., and Shen, K. (2014). Cellular and molecular mechanisms of synaptic specificity. Annu. Rev. Cell Dev. Biol. 30, 417-437. doi: 10.1146/annurev-cellbio100913-012953

Yu, Y. C., He, S., Chen, S., Fu, Y., Brown, K. N., Yao, X. H., et al. (2012). Preferential electrical coupling regulates neocortical lineagedependent microcircuit assembly. Nature 486, 113-117. doi: 10.1038/nature 10958
Zhang, A. J., Jacoby, R., and Wu, S. M. (2011). Light- and dopamine-regulated receptive field plasticity in primate horizontal cells. J. Comp. Neurol. 519, 2125-2134. doi: 10.1002/cne.22604

Zhang, D. Q., Stone, J. F., Zhou, T., Ohta, H., and Mcmahon, D. G. (2004a). Characterization of genetically labeled catecholamine neurons in the mouse retina. Neuroreport 15, 1761-1765. doi: 10.1097/01.wnr.0000135699. 75775.41

Zhang, E. Y., Emerick, R. M., Pak, Y. A., Wrighton, S. A., and Hillgren, K. M. (2004b). Comparison of human and monkey peptide transporters: PEPT1 and PEPT2. Mol. Pharm. 1, 201-210. doi: 10.1021/mp049 9712

Zhu, P., Frank, T., and Friedrich, R. W. (2013). Equalization of odor representations by a network of electrically coupled inhibitory interneurons. Nat. Neurosci. 16, 1678-1686. doi: 10.1038/nn.3528

Zimmermann, M., and Stan, A. C. (2010). PepT2 transporter protein expression in human neoplastic glial cells and mediation of fluorescently tagged dipeptide derivative beta-Ala-Lys-Nepsilon-7-amino-4-methyl-coumarin-3acetic acid accumulation. J. Neurosurg. 112, 1005-1014. doi: 10.3171/2009.6.JNS 08346

Conflict of Interest Statement: The authors declare that the research was conducted in the absence of any commercial or financial relationships that could be construed as a potential conflict of interest.

Copyright $\odot 2016$ Qiao and Sanes. This is an open-access article distributed under the terms of the Creative Commons Attribution License (CC BY). The use, distribution or reproduction in other forums is permitted, provided the original author(s) or licensor are credited and that the original publication in this journal is cited, in accordance with accepted academic practice. No use, distribution or reproduction is permitted which does not comply with these terms. 